\title{
Immunogenicity and feasibility of intradermal vaccination against rabies in Quebec
}

\author{
Bui $\mathrm{Y}^{1,2,3^{*}}$, Sow $\mathrm{M}^{3}$, Cambron-Goulet $\mathrm{E}^{2}$, Levac $\mathrm{E}^{2}$, Milord $\mathrm{F}^{1,2,3}$ \\ ${ }^{1}$ Institut national de santé publique du Québec, Montréal, QC \\ ${ }^{2}$ Direction de santé publique de la Montérégie, QC \\ ${ }^{3}$ Université de Sherbrooke, Sherbrooke, QC \\ *Correspondence author: yen.bui.agence16@ssss.gouv.qc.ca
}

\begin{abstract}
Objectives: Preexposure vaccination against rabies is recommended for some travellers and individuals exposed to the virus through their work. At a cost of at least $\$ 150$ per intramuscular (IM) dose, few follow this recommendation. In Canada, provided certain conditions are met, the National Advisory Committee on Immunization (NACl) and the Comité d'immunisation du Québec allow a more economical alternative, intradermal vaccine administration (ID) which uses $1 / 10$ the IM dose. The purpose of this study is to assess the feasibility and immunogenicity of intradermal preexposure vaccination.

Methods: Students and employees at the Faculty of Veterinary Medicine received three doses of ImovaxRage ${ }^{\mathrm{TM}}$ (Sanofi Pasteur) inactivated, human diploid cell rabies vaccine at days 0, 7 and 21 or 28. An IM or ID booster dose was administered after two years when indicated.

Outcomes: Among the 159 participants who received three doses, 139 underwent serological testing in the year following vaccination and all achieved protective antibody levels. The antibody level was higher when measured within five weeks of the third dose. When the serological control was performed two years later, $65 \%$ of participants had a $<0.5 \mathrm{IU} / \mathrm{ml}$ titre. Of the $22 / 30$ participants who chose an ID booster, $100 \%$ responded and the average antibody titres were multiplied by 11 , indicating a strong anamnestic response.

Discussion: ID rabies vaccination is immunogenic, economic and could be considered for the booster dose. Protective antibodies decline rapidly after primary immunization by ID, so it would seem prudent to perform a serological control one year later on individuals at high risk of occult occupational exposure. An alternative would be to give these individuals a routine ID booster dose one year after primary vaccination, which would simplify initial treatment and reduce related costs (follow-up, blood sampling, serological tests, etc.). The persistence of protective antibodies after this booster dose should be assessed to determine the need for subsequent serological tests and the ideal interval between tests.
\end{abstract}

\section{Introduction}

Rabies is an infection caused by a rhabdovirus of the Lyssavirus genus. It is transmitted through contact with the saliva of an infected mammal, usually by a bite. There is no way to diagnose the disease prior to its clinical stage (1). The virus causes acute, progressive encephalomyelitis, which is almost invariably fatal once symptoms appear, except in very rare cases where individuals manage to survive (2).

Worldwide, more than 50,000 rabies-related deaths are reported every year. Most cases are caused by dog bites and occur in Asia, Africa and South America. India alone accounts for 20,000 rabies-related deaths per year (1). Travellers who visit areas where rabies is highly endemic are at risk, especially if they travel in rural areas (3). In several European countries, most reported human cases are imported and occur among travellers (4).

In Canada, only 24 cases of human rabies were reported from 1924 to 2009 (5) and the last three cases were attributed to bats. Moreover, most cases of rabies occur through contact with an infected bat $(6,7)$, even though the red fox is the main reservoir of terrestrial rabies. Although cases of animal rabies in Canada decreased from 670 in 2000 to 141 in 2012 (8), the animal reservoir of rabies is still extensive (5). People who have contact with animals in their work, such as veterinarians, are at higher risk of exposure to the rabies virus. 
In addition to intramuscular (IM) administration, the World Health Organization (WHO) allows intradermal (ID) administration of rabies vaccines that are prepared in cell culture or embryonated eggs, provided they contain $2.5 \mathrm{IU}$ per dose $(6,9)$. This measure is used primarily in developing countries to promote use of these postexposure vaccines, which cost more, but are much more effective and cause far fewer severe side effects than vaccines prepared from animal nerve tissue $(1,6)$. A protocol for postexposure ID vaccination was introduced for the first time in Thailand in 1984 and subsequently implemented successfully in various countries including India, the Philippines, Sri Lanka and Thailand $(10,11)$.

Both the WHO and the National Advisory Committee on Immunization (NACl) in Canada endorse ID administration of preexposure rabies vaccine. This practice reduces the costs of preexposure vaccination, which is not funded by the Canadian public health system because each dose of the vaccine costs between $\$ 150$ and $\$ 180$. It also simplifies postexposure procedures, eliminating the need for rabies immunoglobulin and reduces the required number of vaccine doses from four to two (12).

In Quebec, vaccination is governed by the Protocole d'immunisation du Québec (PIQ), which was produced by Quebec's Ministry of Health and Social Services and endorsed by a scientific advisory committee, the Comité d'immunisation du Québec. Under PIQ, preexposure rabies vaccines can be administered with a 0.1-ml ID dose or a 1-ml IM dose, using either of the two vaccines approved in Canada, RabAvert ${ }^{\mathrm{TM}}$ (Novartis) purified chick embryo cell rabies vaccine, or ImovaxRage ${ }^{\mathrm{TM}}$ (Sanofi Pasteur) human diploid cell rabies vaccine, both recognized as immunogenic and considered interchangeable (13). ID administration requires good technique to avoid subcutaneous injection and storage regulations and aseptic technique must be followed (6). In addition, according to the Canadian Immunization Guide and PIQ, a serological test is required after ID vaccination for documenting immune response because no ID formulation is approved in Canada. Finally, it is more economical to vaccinate multiple individuals at each session. For all these reasons, this route of administration is seldom used.

Several studies throughout the world have demonstrated the immunogenicity of intradermal preexposure vaccination $(14,15,16,17)$. In addition, the increase in antibody levels achieved by administering an IM or ID booster dose in individuals who previously received ID vaccination is similar to that achieved in individuals who previously received IM vaccination, indicating a good anamnestic response $(18,19)$.

The aim of this study was to assess the immunogenicity and feasibility of ID rabies vaccination in Canada. This could systemize the availability of the vaccine portfolio to risk groups and improve access to the rabies vaccine.

\section{Methodology}

The Université de Montréal Faculty of Veterinary Medicine in St-Hyacinthe, Quebec, Canada has a service agreement with the Richelieu-Yamaska Health and Social Services Centre (CSSS) to offer preexposure rabies ID vaccination at a lower cost to the Faculty's students and employees. In the fall of 2006, participants were recruited by letter, on a voluntary basis to receive the ID rabies vaccine. Pregnant women, individuals under 18, previously vaccinated individuals, those with a history of severe allergic reaction to a previous dose of the vaccine or one of its components, as well as people taking or beginning to take chloroquine within one month after vaccination were excluded.

ImovaxRage ${ }^{\mathrm{TM}}$ (Sanofi Pasteur) vaccine was utilized. It is a freeze-dried human diploid cell vaccine (HDCV), containing $2.5 \mathrm{IU} / \mathrm{ml}$ (13). Given the absence of formulations for ID injection in Canada, vaccination sessions involved sufficient numbers of participants to allow single-dose 1-ml vials to be split into 0.1-ml doses. In accordance with $\mathrm{PIQ}$, vaccines were stored between 2 and $8^{\circ} \mathrm{C}$ and no doses were administered more than six hours after the product was reconstituted. A strict aseptic technique was used.

Written consent was obtained at the time of vaccination along with permission to send the research team information on immunization dates, demographic data, follow-ups and serological test results. Experienced nurses with good ID injection technique vaccinated participants at the Faculty of Veterinary Medicine between September 11 and November 6, 2006. Three 0.1-ml doses were administered in the deltoid muscle on days $0,7,21$ or 28 . A 
telephone and mail reminder system was introduced. A form was used to gather demographic information on participants and serious or unexpected clinical events occurring after vaccination.

An initial serological test was prescribed from two to four weeks after the third dose of the vaccine, which is the interval recommended by PIQ (13) to confirm immunity. For people whose antibody assay was less than 0.5 $\mathrm{IU} / \mathrm{ml}$, an additional dose of the vaccine by IM or ID was offered. A second serological test was recommended for these people to confirm adequate immune response.

For those who had an adequate immune response, a serological control was performed two years after completion of the vaccine series to verify antibody persistence. At this stage, the subjects could choose to receive an ID or IM booster dose if their antibody assay was less than $0.5 \mathrm{IU} / \mathrm{ml}$. All antibody assays were performed in Toronto at the Canadian national rabies reference laboratory using the rapid fluorescent-focus inhibition test (RFFIT).

The chi-square test or t-test was used to monitor the demographics of participants and to compare those lost to follow-up. The correlation between the time of the first serological test and the antibody assay was measured using the Pearson coefficient. A significance level of 0.05 was used for the analyses and $95 \%$ confidence intervals (Cls) were calculated where appropriate. The research protocol for this study was approved by the RichelieuYamaska CSSS's Ethics Research Committee.

\section{Outcomes}

A total of 159 Faculty of Veterinary Medicine students and employees received the three doses of vaccine (Figure 1) and agreed to allow their information to be sent to the research team. The subjects were 18 to 59 (mean of 23 and median of 22) years of age and $84 \%$ were women. No serious or unexpected clinical events after vaccination were reported.

\section{Figure 1: Flowchart of participant follow-ups}

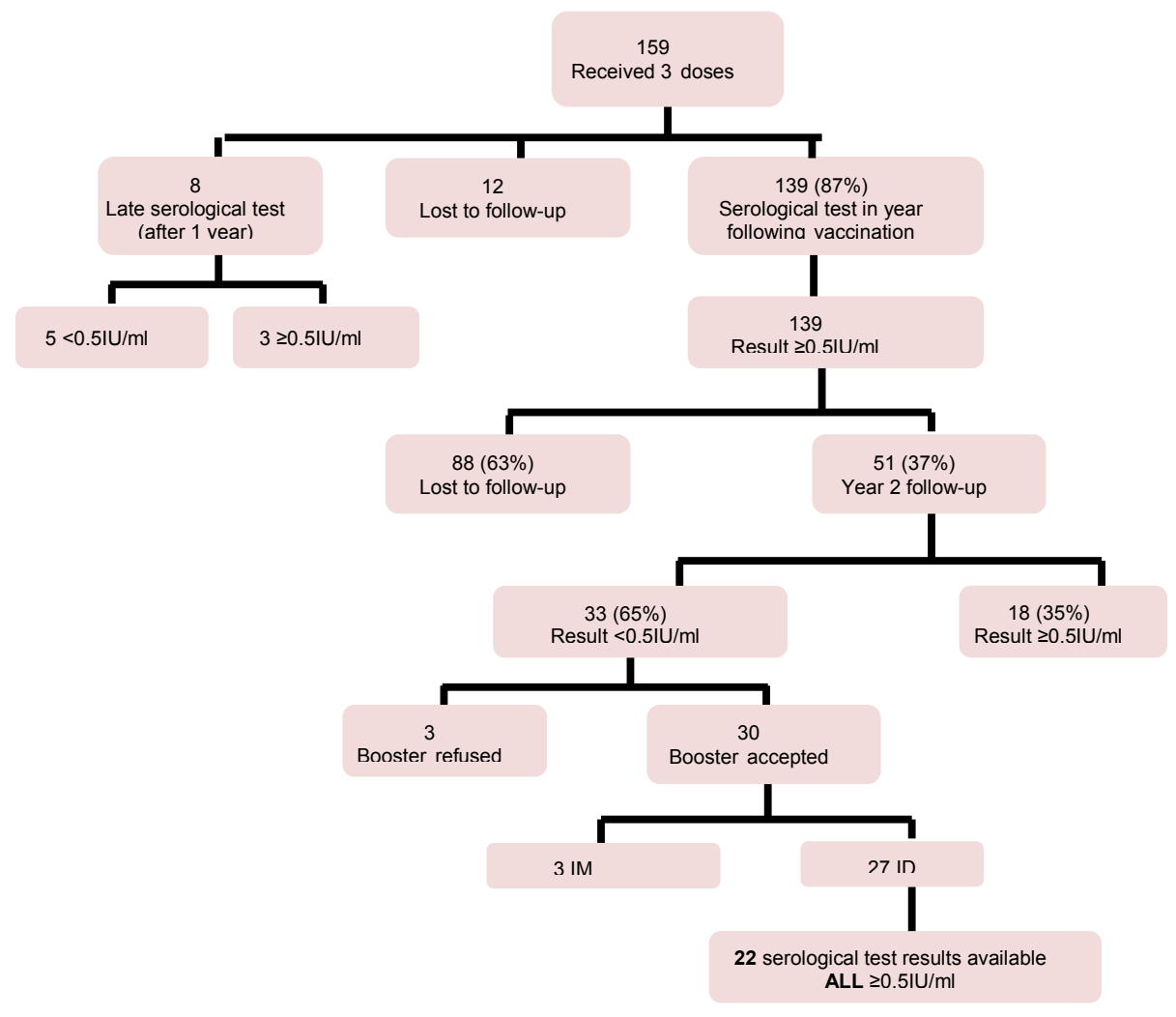


The result of the first serological test was available for 147 people (Figure 2), 139 of who had their serological test within one year of completion of the vaccine series, with an interval ranging from two to 11 weeks between the third vaccine dose and the serological test. Those who had their serological tests done two weeks after the third dose had a $6.1 \mathrm{IU} / \mathrm{ml}$ mean antibody concentration, while this concentration averaged $2.6 \mathrm{IU} / \mathrm{ml}$ if the serological test was performed five weeks after the third dose. There is a negative correlation in the time between the third dose and antibody concentration antibodies: $r=-0.31 ; p<0.05$. Of the eight people who had their serological test done one year or more after vaccination (the deadline was up to 161 weeks), five had a score $<0.5 \mathrm{IU} / \mathrm{ml}$.

Figure 2: Geometric mean titres (IU/ml) based on time after third dose ( $\mathrm{N}=147)$

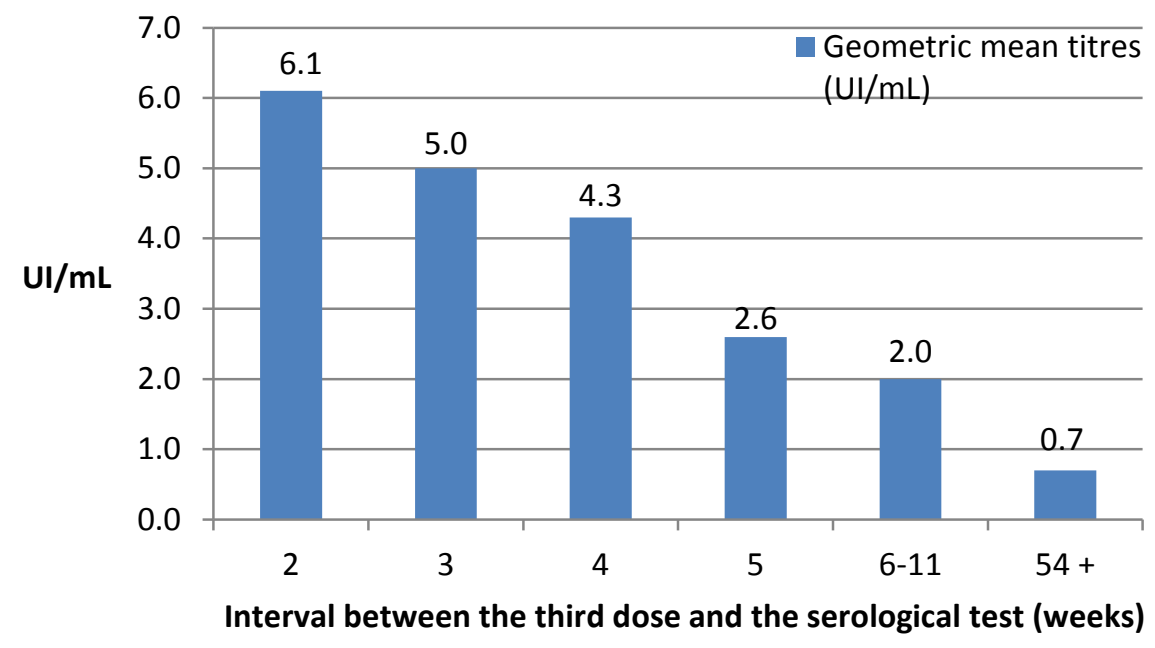

Of the 139 participants (87\%) who had their serological test done in the first year (from 2 to 11 weeks after the 3rd dose), $100 \%$ achieved a $\geq 0.5 \mathrm{IU} / \mathrm{ml}$ rabies antibody titre (Table 1). Two years after completion of the vaccination series, 51 participants reported for serological control. Although there was a general decrease in antibodies between the first and second serological tests, 35\% (18/51) still had a protective level of rabies antibodies. According to the results available for 22 participants who agreed to have the ID booster, $100 \%$ achieved rabies antibody levels $\geq 0.5 \mathrm{IU} / \mathrm{ml}$ and there was a sharp increase in antibody concentrations (Table 1). There was no difference in the average age of participants who reported for follow-up and those lost to follow-up (22 versus 24 years of age, $p=0.44)$ and the percentage of women $(82 \%$ versus $85 \%, p=0.63)$.

Table 1: Antibody titre (IU/ml) after the 3rd dose, at the serological control two years later and after the booster dose

\begin{tabular}{|l|c|c|c|}
\hline \multicolumn{1}{|c|}{ Variables } & $\begin{array}{c}\text { First serological test } \\
(\mathbf{2}-11 \text { weeks after the } \\
\text { 3rd dose })\end{array}$ & $\begin{array}{c}\text { Follow-up serological } \\
\text { testing after 2 years }\end{array}$ & $\begin{array}{c}\text { Serological test after } \\
\text { booster dose }\end{array}$ \\
\hline Number of cases & 139 & 51 & 22 \\
\hline $\begin{array}{l}\text { Average concentration } \\
\text { of antibody titres (IU/ml) } \\
{[95 \% \mathrm{Cl}]}\end{array}$ & $5.3[4.9-5.7]$ & $0.74[0.4-1]^{1}$ & $4.8[4.1-5.5]$ \\
\hline Range & $0.6-10.0$ & $0.1-5.7$ & $1.5-7.4$ \\
\hline Protective antibody titre & $100 \%(139 / 139)$ & $35 \%(18 / 51)$ & $100 \%(22 / 22)$ \\
\hline
\end{tabular}

${ }^{1}$ Excluding a participant who showed an increase in antibody levels between the first and second serological test.

\section{Discussion}

To the authors' knowledge, this is the first study on intradermal preexposure rabies vaccination published in Canada. A total of 159 participants received a series of three $0.1-\mathrm{ml}$ doses of ImovaxRage ${ }^{\mathrm{TM}}$ (Sanofi Pasteur) ID vaccine. No serious adverse effects were noted and it appears that improved injection techniques and the efficacy 
and safety of new generations of rabies vaccines have decreased the negative side effects that were observed following ID administration in the past $(20,21)$. All participants who completed a serological test in the year following the third dose had protective levels of rabies antibodies. These results confirm that ID administration of rabies vaccine is safe and immunogenic in healthy people.

A rapid decrease in antibody titres was observed if the serological test was performed more than five weeks after primary immunization. This study did not include an IM control group to measure whether the route of administration influences the kinetics of the immune response. Some studies have reported that the titres achieved after primary immunization and booster dose were higher by IM than by ID $(18,22,23)$. However, the protective antibody level obtained would be as adequate by ID as by IM $(6,21)$. In addition, it is known that cell culture rabies vaccines provide excellent immune memory and several studies have demonstrated an anamnestic response after a booster dose in individuals previously vaccinated by ID $(19,24,25,26)$.

The results of this study demonstrate that two years after primary immunization, rabies antibodies persist at varying levels, with $35 \%$ of subjects still showing a protective titre. After administration of the booster dose, $100 \%$ of participants for whom serological test results were available developed an anamnestic response with mean antibody titres multiplied by 11 . All participants in this study were 18 years of age and older and a large majority were women, reflecting the demographics of the students in the Faculty of Veterinary Medicine. No significant differences between age and sex groups were identified in this study nor in the literature (26). The demographics of participants lost to follow-up were similar to those of participants who completed the study.

Several studies have shown that memory response to a booster dose may be induced years after primary immunization, even among those whose antibody titres fell below the $0.5 \mathrm{IU} / \mathrm{ml}$ threshold considered protective $(26,27)$. Malerczyk et al reported an anamnestic response to a booster dose in individuals vaccinated 15 years earlier (25) and other studies report an anamnestic response to a booster dose to up to 21 years after primary immunization (6).

In recent years, the emergence of rabies was observed in southern Quebec with the migration of a new strain of raccoon rabies from the United States $(27,28)$. Participants in this study were veterinary students working in an enzootic area. However, the results of this study revealed that antibody levels declined rapidly after the third dose and that a number of recipients already had titres below $0.5 \mathrm{IU} / \mathrm{ml}$ one year after primary immunization. A systematic review conducted in England reported that up to $13 \%$ of recipients' antibody levels decreased to $<0.5$ $\mathrm{IU} / \mathrm{ml}$ one year after IM primary immunization (29). Since antibody titres may be lower with the ID route $(25,26)$, antibodies are expected to decrease more quickly after the vaccine is administered through this route. The results point in the same direction suggesting that for groups at risk of occult exposure, the date of the first serological control and administration of the $1^{\text {st }}$ booster dose be moved up from two years to one year. This recommendation would ensure that these individuals' antibody titres do not fall below the protective threshold.

Currently, it takes at least six to eight weeks to obtain serological test results. In addition, patient follow-ups and reminders for blood samples require substantial resources and the number of patients lost to follow-up remains problematic (63\% in this study). More studies are needed to document the persistence of protective antibodies after ID primary immunization and after an ID booster dose, but it is likely that an ID booster administered after one year could provide protection long enough (5) to extend the time between subsequent serological controls.

It also appears that cell culture vaccines are highly immunogenic and protective antibody titres after a booster dose can last up to five years in $96.2 \%$ of cases $(5,6)$. Research has shown that a booster dose administered one year after the primary immunization series could induce protective antibodies lasting up to 10 years (30) and that subjects who achieved a titre $\geq 30 \mathrm{IU} / \mathrm{ml}$ could receive a booster every 10 years and every three years for those with a titre $<30 \mathrm{IU} / \mathrm{ml}$. This course of action would eliminate the need for serological tests every two years.

Five participants who completed their serological test one year or more after the third dose achieved a result below the protective threshold. With the data provided in this study, it is not known whether this is a primary failure of vaccination or an expected gradual decline in antibody concentrations over time. Given the excellent immune response in 139 participants who completed their serological tests during the first year, it is assumed that if serological testing had been done sooner after primary immunization, those five individuals could have achieved an adequate antibody level. 
The economic benefits of this injection route were directly observed during vaccination sessions. A 1-ml vial of rabies vaccine was sufficient to vaccinate seven to eight people intradermally. The CSSS established the cost per dose of ID vaccine at $\$ 60$, three times less than for an IM dose. The net savings calculation should take into account the cost of nursing time required for the ID technique, the costs of serological tests, follow-ups and results monitoring. It was also observed that $90 \%$ of participants whose rabies antibody level was $<0.5 \mathrm{IU} / \mathrm{ml}$ after two years, chose to receive the booster dose via the ID route, even if they had to complete another serological test to document the response.

It is also known that few travellers get the rabies vaccine, e.g., a study at Bangkok Airport involving 7,681 foreign travellers revealed that only $12 \%$ had completed their vaccination series, $15 \%$ received one or two doses, while $73 \%$ had not been vaccinated at all (31). The risk of being bitten when travelling in endemic areas is difficult to assess. A study involving 1,882 tourists visiting Thailand for an average of 17 days estimated that $1.3 \%$ of them had been bitten (32). It is essential to reduce costs in order to make the vaccine more readily available to groups with occupational risk, such as the study participants or travellers in endemic areas. Another benefit of preexposure vaccination is that travellers bitten while abroad would no longer need rabies immunoglobulins, which are either in very short supply or unavailable in most developing countries (6) and recipients would also require fewer vaccine doses for postexposure. In addition, travellers, who are not considered at risk of occult exposure to the rabies virus, do not have to receive a booster dose or undergo repeated serological controls.

Other intradermal preexposure vaccination schedules were studied around the world, such as simultaneous administration of two ID injections (one in each deltoid area) at days $0,7,21$ or 28 , at days $0,3,7$ or only at day 0 (19). Regardless of the schedule, a strong anamnestic response was observed one year later, after two booster vaccinations. Although empirical, it is likely that these practices would be helpful in cases where high-risk travellers are scheduled to leave shortly and there is not enough time to perform serological tests.

In November 1982, a U.S. Peace Corps volunteer in Kenya completed preexposure rabies prophylaxis with a standard three dose intradermal (ID) series of human diploid cell rabies vaccine (33). In May 1983, she was bitten by a dog, but did not consult a health professional for postexposure vaccination and subsequently died of rabies. A serological test performed when her symptoms appeared revealed an inadequate antibody titre. At the same time, serological tests performed on other Peace Corps volunteers who also received ID vaccination revealed that nine of the 11 subjects had inadequate antibody titres. Although response after primary vaccination did not seem adequate, the survey considered that if two doses had been administered postexposure as recommended the death could have been avoided. This highlights the importance of serological control after primary intradermal vaccination to ensure antibody levels are $\geq 0.5 \mathrm{IU} / \mathrm{ml}$. This incident and the recall of three lots of an approved rabies ID vaccine with insufficient antigen levels, led to the withdrawal of ID vaccines from the US market in 2001, even if the immunogenicity of the ID route was not called into question (3).

Intradermal vaccination is still offered at the Université de Montréal Faculty of Veterinary Medicine. Between 2007 and 2013 , nearly 1,000 people were vaccinated and serological tests performed two to four weeks after the third dose produced only two results $<0.5 \mathrm{IU} / \mathrm{ml}(0.36$ and $0.47 \mathrm{IU} / \mathrm{ml}$, respectively) (Jocelyne Angers, personal communication, July 2014). This route is always well tolerated and RabAvert ${ }^{\mathrm{TM}}$ and ImovaxRage ${ }^{\mathrm{TM}}$ vaccines are used interchangeably during vaccination sessions which facilitates vaccine stock management.

The results of this study demonstrate that administering the vaccine intradermally using $1 / 10^{\text {th }}$ of the IM dose is an immunogenic, economic and feasible alternative where groups of clients can be scheduled for vaccination by qualified staff using good techniques and when there is enough time for post-vaccination serological testing. All these conditions were fulfilled in this study at the Faculty of Veterinary Medicine. Because antibody titres decline rapidly during the first year, it would be prudent to provide individuals at high risk of occult exposure to rabies with a booster dose one year after primary vaccination without prior serological testing. Serological follow-up to document the persistence of antibodies should be performed subsequently to determine the need and most appropriate time for other booster doses.

Availability of an approved ID formulation in Canada and shorter serological test times would ease the logistical problems encountered in this study. 


\section{Acknowledgements}

The authors would like to thank the students and staff at the Université de Montréal Faculty of Veterinary Medicine for their contribution to this study. A big thank you is also extended to the entire Richelieu-Yamaska CSSS team and in particular to Francine Lord and Danielle Bisson for logistics. Anne-Marie Clouâtre, Dr. Lina Perron and Dr. Louise Lambert of the Direction de santé publique de la Montérégie are also acknowledged with gratitude for providing a critical review of the project and Nathalie Bernier and Marianne Picard-Masson for their various analyses.

\section{Conflict of interest}

None

\section{References}

(1) World Health Organization. Rabies vaccines. Wkly Epidemiol Rec. 2010;85(32):309-20.

(2) Willoughby RE, Tieves KS, Hoffman GM, Ghanayem NS, Amlie-Lefond CM, Schwabe MJ, Chusid MJ, Rupprecht CE. Survival after treatment of rabies with induction of coma. N Engl J Med. 2005;352(24):2508-14.

(3) Rupprecht CE, Shlim DR. Rabies. In: Centers for Disease Control and Prevention (CDC). CDC Health Information for International Travel 2014. New York: Oxford University Press, 2014:270-6.

(4) Comité consultatif de la médecine tropicale et des voyages. Déclaration relative aux voyageurs et au vaccin contre la rage. RMTC2002;28. http://www.collectionscanada.gc.ca/webarchives/20071116052847/. http://www.phacaspc.gc.ca/publicat/ccdr-rmtc/02vol28/28sup/dcc4.html

(5) Agence de santé publique du Canada. Guide canadien d'immunisation. Partie 4 - Vaccins inactivés, Vaccins contre la rage. http://www.phac-aspc.gc.ca/publicat/cig-gci/p04-rabi-rage-fra.php\#voyageurs. (Available in English: http://www.phac-aspc.gc.ca/publicat/cig-gci/p04-rabi-rage-eng.php).

(6) World Health Organization. WHO expert consultation on rabies. World Health Organ Tech Rep Ser. 2005;931:1-88. http://whqlibdoc.who.int/trs/WHO_TRS_931_eng.pdf.

(7) De Serres G, Dallaire F, Côte M, Skowronski DM. Bat rabies in the United States and Canada from 1950 through 2007: Human cases with and without bat contact. Clin Inf Dis. 2008;46:1329-37.

(8) Agence canadienne d'inspection des aliments. Cas de rage positifs au Canada - Rage chez les animaux. http://epe.lac-bac.gc.ca/100/206/301/cfia-acia/2011-09-

21/www.inspection.gc.ca/francais/anima/disemala/rabrag/statsf.shtml.

(9) World Health Organization. Updated WHO position paper on rabies vaccines. Geneva: WHO; 2010. http://www.who.int/immunization/Rabies_slides_Aug_2010.pdf.

(10) Chulasugandha $\mathrm{P}$, Khawplod $\mathrm{P}$, Havanond $\mathrm{P}, \overline{\mathrm{W}}$ ilde $\overline{\mathrm{H}}$. Cost comparison of rabies preexposure vaccination with postexposure treatment in Thai children. Vaccine. 2006;24(9):1478-82.

(11) Quiambao BP, Dimaano EM, Ambas C, Davis R, Banzhoff A, Malerczyk C. Reducing the cost of postexposure rabies prophylaxis: Efficacy of $0.1 \mathrm{ml}$ PCEC rabies vaccine administered intradermally using the Thai Red Cross postexposure regimen in patients severely exposed to laboratory-confirmed rabid animals. Vaccine.

2005;23(14):1709-14.

(12) Comité national consultatif de l'immunisation. Mise à jour sur les vaccins antirabiques. RMTC. $2005 ; 31$.

(13) Ministère de la santé et des services sociaux du Québec. Protocole d'immunisation du Québec - 6e édition. Québec: Gouvernement du Québec; 2013.

(14) Lau C, Sisson J. The effectiveness of intradermal preexposure rabies vaccination in an Australian travel medicine clinic. J Travel Med. 2002;9(6):285-8.

(15) Wilde H, Briggs DJ, Meslin FX, Hemachudha T, Sitprija V. Rabies update for travel medicine advisors. Clin Infect Dis. 2003;37(1):96-100.

(16) Ranney M, Partridge R, Jay GD, Rozzoli DE, Pandey P. Rabies antibody seroprotection rates among travelers in Nepal: "Rabies seroprotection in travelers". J Travel Med. 2006;13(6):329-33.

(17) Bui YG, Milord F, Levac E, Lord F. Faisabilité de la vaccination intradermique contre la rage au Québec. Communication par affiche présentée aux 10e Journées annuelles de santé publique. Montréal (QC); 2006. Jijaroensup W, Limusanno S, Kwawplod P, Serikul K, Chomchay P, Kaewchomphoo W, Tantawichien T, Wilde H. Immunogenicity of rabies postexposure booster injections in subjects who had previously received intradermal preexposure vaccination. J Travel Med. 1999;6:234-37.

(19) Khawplod P, Wilde H, Benjavongkulchai M, Srianroon C, Chomchey P. Immunogenicity study of abbreviated rabies preexposure vaccination schedules. J Travel Med. 2007;14(3):173-6.

(20) Briggs DJ, Banzhoff A, Nicolay U, Sirikwin S, Dumavibhat B, Tongswas S, Wasi C. Réponse en anticorps après vaccination antirabique de post-exposition par de petites doses intradermiques de vaccin purifié préparé sur cellules d'embryon de poulet ou sur cellules Vero. Bull World Health Organ. 2000;78:693-8.

(21) World Health Organization. WHO position paper on rabies vaccine - Table III: Safety of cell-culture-based rabies vaccines. Geneva; 2010. http://www.who.int/immunization/rabies_grad_safety.pdf. 
(22) Kositprapa C, Limsuwun K, Wilde H, Jaijaroensup W, Saikasem A, Khawplod A, Kri-aksorn U, Supich C. Immune response to stimulated postexposure rabies booster vaccinations volunteers who received preexposure vaccinations. Clin Inf Dis. 1997;25:614-6.

(23) Nicholson KG, Turner GS, Aoki FY. Immunization with a human diploid cell strain of rabies virus vaccine: Two-year results. J Infect Dis. 1978;137(6):783-8.

(24) Suwansrinon K, Wilde H, Benjavongkulchai U, Lertjarutorn S, Boonchang S, Suttisri R, Khowplod P, Daviratanasilpa S, Sitprija V. Survival of neutralizing antibody in previously rabies vaccinated subject: A prospective study showing long lasting immunity. Vaccine. 2006;24(18):3878-80.

(25) Malerczyk C, Briggs DJ, Dreesen DW, Banzhoff A. Duration of immunity: An anamnestic response 14 years after rabies vaccination with purified chick embryo cell rabies vaccine. J Travel Med. 2007;14(1):63-4.

(26) Brown D, Featherstone JJ, Fooks AR, Gettner S, Lloyd E, Schweiger M. Intradermal preexposure rabies vaccine elicits long lasting immunity. Vaccine. 2008;26:3909-12.

(27) Chang HG, Eidson M, Noonan-Toly C, Trimarchi CV, Rudd R, Wallace BJ, Smith PF, Morse DL. Public health impact of reemergence of rabies, New York. Emerg Infect Dis. 2002;8(9):909-13.

(28) Blanton JD, Dyer J, McBrayer J, Rupprecht CE. Rabies surveillance in the United States during 2011. J Am Vet Med Assoc. 2012;241(6):712-22.

(29) Morris J, Crowcroft NS. Preexposure rabies booster vaccinations: A literature review. Dev Biol (Basel). 2006;125:20515.

(30) Strady A, Lang J, Lienard M, Blondeau C, Jaussaud R, Plotkin SA. Antibody persistence following preexposure regimens of cell-culture rabies vaccines: 10 -year follow-up and proposal for a new booster policy. $\mathrm{J}$ Inf Dis. 1998;177:1290-5.

(31) Piyaphanee W, Kittitrakul C, Lawpoolsri S, Gautret P, Kashino W, Tangkanakul W, Charoenpong P, Ponam T, Sibunruang S, Phumratanaprapin W, Tantawichien T. Risk of potentially rabid animal exposure among foreign travelers in Southeast Asia. PLoS Negl Trop Dis. 2012;6(9):e1852. doi: 10.1371/journal.pntd.0001852.

(32) Phanuphak $\mathrm{P}$, Ubolyam S. Should travelers in rabies endemic areas receive preexposure rabies immunization? Presentation at the International Conference on Travellers' Medicine. Atlanta (GA); 1991.

(33) Bernard KW, Fishbein DB, Miller KD, Parker RA, Waterman S, Summer JW, Reid FL, Johnson BK, Rollins AJ, Oster $\mathrm{CN}$ et al. Preexposure rabies immunization with human diploid cell vaccine: Decreased antibody responses in persons immunized in developing countries. Am J Trop Med Hyg. 1985;34(3):633-47. 